\title{
Edifícios e habitações sociais humanizados para idosos
}

\author{
Buildings and humanized social housing for \\ elderly
}

Elizabeth Sério Barbosa ${ }^{1}$

Dra. Eliete de Pinho Araujo²
1 Estudante do Curso de Arquitetura e Urbanismo do Centro Universitário de Brasília - UniCEUB. Projeto de Iniciação Científica - PIBIC 2010.

2 Arquiteta, Professora no Curso de Arquitetura e Urbanismo do UniCEUB. Doutora pela ENSP - FIOCRUZ.

\section{Resumo}

Este projeto de pesquisa tem por objetivo estudar linhas de trabalhos voltados para a humanização dos espaços arquitetônicos para os idosos, reconhecendo a influência da arquitetura sobre o comportamento humano e suas contribuições para uma melhor qualidade de vida e suas aplicações em projetos habitacionais sociais em edifícios de baixa altura, ou seja, de no máximo 3 (três) pavimentos e residências multifamiliares. A pesquisa bibliográfica responde a questionamentos de como deve ser o desenvolvimento de um programa adequado ao edifício habitacional social, dependente diretamente do grau de conhecimento das pessoas que irão utilizar este espaço e suas necessidades. Também apresenta o conceito de Desenho Universal como possibilidade de projeto humanizado inclusivo que pratica uma arquitetura para todos, conceito este que vai além do cumprimento automático de normas vigentes, sem considerar uma reflexão sobre sua importância e benefícios para os usuários. Apresenta também conceitos de concepção de projetos sociais para idosos, segundo a perspectiva de John Zeisel, sociólogo, arquiteto e professor norte-americano, especialista em arquitetura comportamental e Herman Hertzberger, arquiteto holandês que desenvolveu o conceito de arquitetura estruturalista. Como obra de referência, foi estudado o projeto desenvolvido pelo escritório Aflalo \& Gasperini em conjunto com o Governo do Estado de São Paulo, em Avaré (SP), com o objetivo de promover habitação e áreas de convivência social para idosos de baixa renda. O trabalho de pesquisa é finalizado com o desenvolvimento de estudo preliminar de projeto para Instituição de Longa Permanência para Idosos (ILPI), que se constitui em um exercício de fixação dos conceitos e normas técnicas estudadas.

Palavras-chave: Habitação. Humanização. Qualidade de vida. Democratização. Comportamento humano. Arquitetura inclusive. Arquitetura comportamental.

\begin{abstract}
This research project aims to study how lines of work focused on the humanization of the architectural spaces for the elderly, recognizing an influence of architecture on human behavior and his contributions to a better life quality for the elderly, their applications in social housing projects in buildings of low height and single-family residences. The bibliographical research responds to questions how it should be the development of a suitable social housing building program which depends on the degree of knowledge of the people who will use this space and your needs. Introduces the concept of Universal design as a possibility of $\mathrm{Hu}-$ manized design inclusive that practices an architecture for everyone, this concept goes beyond compliance with existing standards, automatic without considering a reflection about its importance and benefits for users. Concepts of designing social projects for the elderly are showed, according to the perspective of John Zeisel, a sociologist and architect, and Herman Hertzberger, architect who developed the concept of structuralist architecture. As case of study, a project developed by Aflalo \& Gasperini in conjunction with the Government of the State of São Paulo is showed, in Avaré (SP-Brazil), with the aim of promoting social housing and living areas for low-income seniors. It is presented as a preliminary study of project for Institution of Long permanence (ILPI), which is carrying out the concepts and technical standards
\end{abstract}

Keywords: Housing. Humanization. Quality of life. Democratization. Human behavior. Inclusive architecture. Behavioral architecture. 


\section{Introdução}

Nos dias de hoje, os arquitetos vêm demonstrando postura comportamental na forma de projetar que vai além do cuidado com a estética, a função, o uso de bons materiais e inclusão de estratégias de conforto ambientais. Inclui em suas concepções de projetos o cuidado em atender as expectativas de usuários menos capazes com cuidados que vão além do cumprimento de normas específicas (ABNT 9.050/2000) e conferindo um caráter humanitário à arquitetura (Desenho Universal). Esta arquitetura humanizada não faz distinção entre capazes e não capazes, jovens e idosos, o que se concebe como sendo uma arquitetura inclusiva, ou seja, para todos. E, por assim se constituir complexa, está imbuída da participação de profissionais de diversas áreas de atuação na medida em que envolve processos distintos que visam atender os programas específicos de portadores de necessidades especiais e que são condições essenciais para a construção de verdadeiros centros sadios de convivência humana.

O perfil da população brasileira está mudando. O número de pessoas com idade de 60 anos ou mais, é tema recorrente em jornais, televisão e centros educativos. São pessoas que muitas vezes se aposentam ainda em fase produtiva e com objetivos pessoais que muitas vezes não se realizam. E por não serem capazes de se manter economicamente, por vezes são colocados em asilos, que o transformam em ser totalmente incapaz, não respeitando a sua incapacidade parcial e a necessidade de socialização.

As estratégias de projetos arquitetônicos propostos neste trabalho têm por base pesquisa bibliográfica e estudo de projetos de arquitetos com obras construídas e publicações sobre edificações de longa permanência para o idoso e clínicas especializadas em geriatria, que visam integrar o idoso na sociedade $\mathrm{e}$ não seu isolamento e segregação social. O estudo está divido em etapas como análise da população de idosos brasileiros, conhecimento do que é ser idoso, suas dificuldades, limitações e necessidades, a busca por obras de referências e estudos práticos. As soluções de projetos para edificações para idosos foram encontradas em edições públicas e obras executadas de arquitetos que seguem linhas humanísticas de arquitetura com resultado positivo comprovado, apresentadas neste trabalho de pesquisa.

\section{Revisão da bibliografia / fundamentação teórica}

\subsection{Entendendo o idoso como portador de necessi- dades especiais}

Com a idade, a vida da pessoa pode ser afetada de várias maneiras e surgem algumas semelhanças entre os idosos, que não são compartilhadas com os mais jovens. Para alguns idosos, o envelhecimento pode significar solidão, ou maior dependência dos outros, menor força física e coordenação. As pessoas mais velhas tendem a experimentar uma sensação de perda de posição social. Com a aposentadoria e menos obrigações familiares, os idosos encontram mais tempo para o lazer, mas as oportunidades em conhecer e conviver com outras pessoas diminuem. Isso os leva a retirar-se da sociedade e a ficar ainda mais dependentes de seu ambiente residencial. Com o aumento de doenças crônicas, torna-se ainda mais difícil e dolorosa a locomoção, o que limita ainda mais o seu espaço de atividades cotidianas.

Envelhecer significa também uma redução da capacidade sensorial, perda de visão, audição e senso de equilíbrio e diminuição de suas habilidades para responder aos estímulos do ambiente. Problemas de visão incluem a perda da visão periférica, a inabilidade de distinguir objetos, a dificuldade de leitura e sensibilidade à claridade. Aqueles com problemas de audição têm dificuldade em entender os outros em reuniões de grupos, assim como em conversas normais. Com a diminuição dos sentidos, os idosos recebem menos informações sobre o que acontece ao seu redor e seu senso de perceber o ambiente pode ficar comprometido por configurações complicadas e mal demarcadas. Essa sensação de incompetência pode confirmar a necessidade do idoso em se retirar do convívio social.

\subsection{Recomendações de projetos voltados para o idoso}

Os idosos têm necessidades especiais que diferem daqueles associados com outras faixas etárias e algumas vezes, entre eles mesmos, uma vez que têm origens, estilos de vida e atitudes diferentes entre si. Algumas adaptações no ambiente podem ser atendidas por modificações no projeto habitacional, porém, em outros casos, necessitam de maiores detalhes de planejamento, tais como, altura e localização dos degraus de escadas, tipos de maçanetas, localização de tomadas e interruptores de luz, entre ou- 
tros. Tais questões devem ser abordadas na concepção de um projeto que seja sensível às necessidades dos idosos por profissionais conscientes de como a adição de certos elementos podem tornar a vida dos idosos mais confortáveis.

\subsection{Soluções de Projetos Humanizados}

A busca por informações e conhecimentos de soluções de projetos arquitetônicos humanizados voltados para idosos deve ser um processo permanente e contínuo a ser trabalhado em conjunto por profissionais de várias áreas, sejam arquitetos, designers, psicólogos, sociólogos, neurocientistas, pesquisadores, entre outros. A cada busca, encontram-se novas respostas que apontam para soluções inovadoras, que mostram existir muitas maneiras de acomodar as necessidades de residências para idosos.

Encontrar soluções que atendam às necessidades sociais dos idosos é parte de um processo complexo que incluem tomadas de decisões sobre fatores físicos, de desenvolvimento projetual, de construção, bioclimáticos, econômicos, tecnológicos, entre outras. São elas:

- inclusão de áreas que respeitem a individualidade e outras de convivência social, sem que isso remeta ao isolamento não favorável à saúde física e mental do idoso;

- especificação de mobiliário adaptado às limitações de cada usuário proporcionando conforto e segurança, e criação de espaços humanizados, aconchegantes e agradáveis;

- questões relativas à iluminação e ventilação naturais, paisagismo, telhados verdes, áreas de convivência social e espaços individualizados, evitando, assim, ambientes destinados ao confinamento pelo uso de sistemas artificiais de climatização;

- criação de situações que remetam o usuário às lembranças de situações que contribuam para uma boa recuperação e sejam agradáveis à permanência no espaço;

- possibilidades de requalificação e readequação de espaços.

São referências em Arquitetura Humanizada os conceitos de Desenho Universal ou Arquitetura Inclusiva e suas aplicações em projetos de arquitetura e estudos e obras de arquitetos como John Zeisel (1977) e Herman Hertzberger (1996) e seu conceito de Arquitetura Estruturalista.

\section{Metodologia}

Esta pesquisa foi elaborada a partir de levantamento de pesquisa bibliográfica, publicações como cartilhas, pesquisas em sites especializados, legislações e normas técnicas relacionadas ao tema. Como estudo de casos, são apresentados dois projetos que são a Vila Dignidade de Avaré (SP), onde um conjunto residencial construído para o idoso de baixa renda, com um programa de necessidades que atende ao portador de necessidades reduzidas e que leva à socialização, independência e autoestima e um edifício hospitalar e as soluções encontradas para que residentes e não residentes portadores do Mal de Alzheimer recebam tratamento e atendimento. Foram realizadas visitas em duas instituições de longa permanência para idosos, localizadas em Boa Esperança (MG) e Sobradinho (DF). Com estas entidades não foram realizados levantamentos estatísticos e a pesquisa foi empírica no sentido de buscar o conhecimento pela experiência e vivência dos dirigentes destas instituições e o sentimento que se pode ter quando em contato com o idoso, moradores destas instituições.

\section{Resultado final - Projeto Vila da Alegria}

Como resultado é apresentado o estudo de projeto para uma instituição de longa permanência para idosos (ILPI), em caráter residencial, na cidade de Sobradinho (DF). O pedido partiu do interesse que a entidade tem em construir um local para receber idosos com grau de dependência I, ou seja, aqueles que são independentes para desempenhar tarefas diárias, mesmo que necessitem fazer uso de equipamentos de autoajuda, de acordo com a RDC 283 (2005). Estes espaços serão alugados para idosos capazes de contribuir monetariamente, mesmo que com valor simbólico, com a finalidade de suprir, em parte, com as despesas que a entidade tem com os mais carentes.

$\mathrm{O}$ estudo preliminar apresentado é um exercício de fixação dos conceitos apresentados por John Zeisel e Herman Hertzberger, das normas previstas na ABNT 9.050/2004 e Desenho Universal que resultou no projeto ora apresentado. Compreende as etapas descritas a seguir.

\subsection{Sobre a Instituição de Longa Permanência para Idosos (ILPI)}

A instituição atualmente possui dois edifícios construídos, identificados aqui como EDIF. I e EDIF.II. 
O EDIF. I abriga a residência de uso coletivo para idosos, de ambos os sexos, e toda a infraestrutura física necessária ao atendimento dos residentes, tal como, farmácia, refeitório, cozinha, despensa, depósito, entre outros, de acordo com a RDC 283 (2005). O EDIF. II abriga a área administrativa, salas de fisioterapia e psicólogos, local de convivência com churrasqueira, banheiros, entre outros. Uma área ajardinada com espaço ecumênico e museu da memória faz o vínculo entre EDIF. I e EDIF.II. O TERRENO livre, que fica ao lado da área destinada ao Projeto Vila da Alegria (Figura 01), pode vir a ser destinado para construção de uma loja que funcionará como um brechó. A renda oriunda de produtos vendidos no brechó será revertida para a manutenção da entidade.

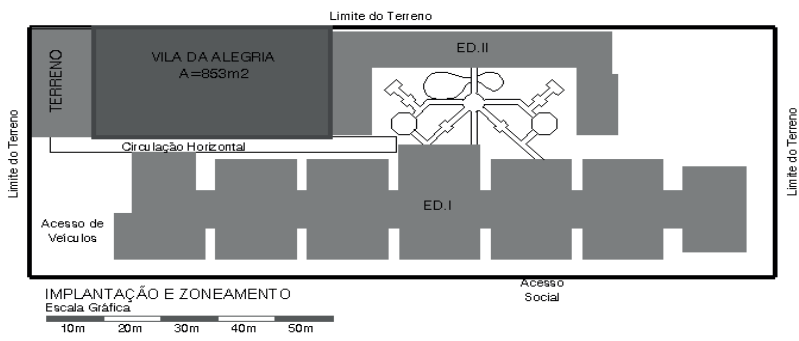

Figura 01 - Implantação do Projeto Vila da Alegria - Sobradinho (DF). Fonte: acervo pessoal.

\subsection{Levantamento do Entorno}

Levantamento realizado indica que a entidade está inserida em local ideal para uma instituição desta natureza, uma vez que possui elementos essenciais a uma boa qualidade de vida, permitindo ao idoso ter independência e ser autossuficiente, com possibilidades de atividades de lazer, educacionais, integração com a comunidade local, tais como:

sistema viário amplo, pontos de ônibus e Terminal Rodoviário de Sobradinho;

Shopping Center, estádio de Futebol Augusto Lima, Campo de Várzea e Parque Horto Florestal; órgão público do DETRAN - Departamento de Trânsito de Sobradinho;

centro educacional Colégio La Salle;

área comercial com presença de supermercado; e bairro residencial.

\subsection{Programa de Necessidades}

Desenvolvido para atender a necessidade da ILPI de Sobradinho (DF), o programa adota as soluções de projetos para habitação social para idosos apresentados por John Zeisel, Herman Hertzberger, de acordo com as normas previstas na NBR 9.050/2004 e conceitos do Desenho Universal, bem como de soluções desenvolvidas pela aluna Elizabeth Sério Barbosa sobre a orientação da Profa. Eliete de Pinho Araújo. Está dividido em 4 (quatro) áreas de zoneamento principais, conforme demonstrado na Figura 02.

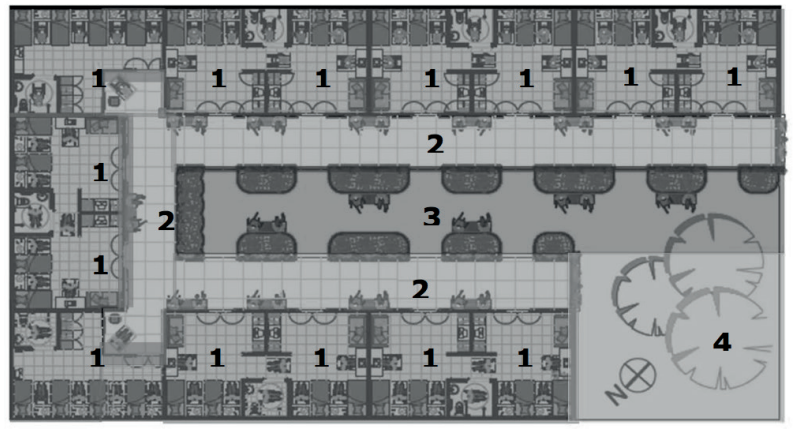

Figura 02 - Diagrama de zoneamento da Vila da Alegria. Fonte: acervo pessoal.

Legenda

1 = Área privativa - quartos e banheiros.

2 = Área comum - varanda.

3 = Área comum - pátio central.

4 = Área comum - praça comunitária

As áreas privadas compreendem os apartamentos e banheiros adaptados, as áreas comuns ou coletivas compreendem os espaços de lazer e convivência e acontecem na varanda e pátio central. A praça coletiva faz a vinculação da Vila da Alegria com as demais edificações da instituição.

Para os apartamentos são apresentadas duas soluções de projetos com a finalidade de ocupar a área total destinada ao projeto. Cada opção de planta contempla número máximo de 4 (quatro) leitos e um banheiro adaptado que atende a estes 4 residentes. O projeto prevê para todos os apartamentos espaço para armários e estantes individuais, mesa pequena para atividades diárias e TV.

\subsection{Partido de Projeto}

A intenção do projeto é criar um espaço alegre e mudar a ideia que todos têm de que uma habitação para idosos não possa ser esteticamente bela, harmoniosa, confortável e agradável a todos, independentemente da faixa etária.

Busca na memória do idoso o referencial que cada um tem de sua cidade natal e de seus elementos tradicionais como casas com janela para a rua, cobertura de telhas coloniais, sistema construtivo de alvenaria e ma- 
deira, praça da matriz e vegetação nativa da cidade de Pirenópolis (GO) (Figuras 03 e 04).

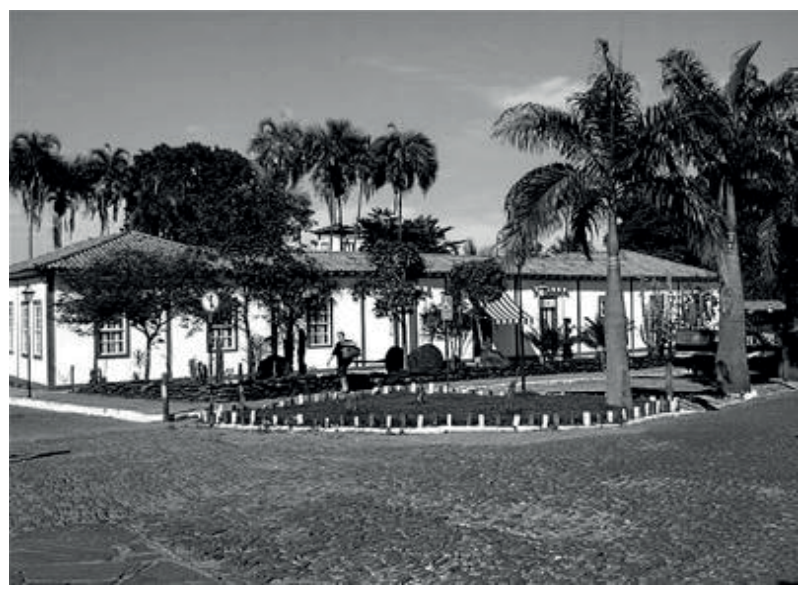

Figura 03 - Referência de partido de projeto - Centro Histórico de Pirenópolis.

Fonte: acervo pessoal

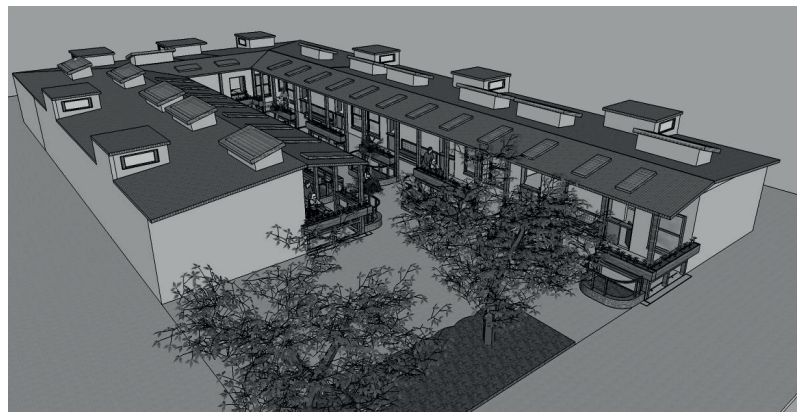

Figura 04 - Vila da Alegria - Imagem comparativa do uso de referências de projeto.

Fonte: acervo pessoal

O partido de projeto da Vila da Alegria parte do princípio de que os idosos devem permanecer o menor tempo possível dentro de seus quartos. Grandes janelas dispostas em frente aos leitos fazem com que o idoso acamado acompanhe todo o movimento que acontece fora do quarto. Assim, a área de circulação (varanda), em frente aos dormitórios, servirá como uma rua onde o idoso tem vários bancos para assentar, descansar e conversar com os outros residentes. Uma vez fora dos quartos e já assentado nos bancos da rua (varanda), terá o incentivo de caminhar um pouco mais e ocupar bancos que ficam na praça central. Tal caminhar, do leito até os bancos que ficam na praça central será, intuitivamente, guiado pela iluminação natural dos espaços e pela mudança tátil do piso, o que será explicado com mais detalhes nos itens Iluminação Natural e Piso.

\subsection{Desenvolvimento do Projeto}

Para o projeto Vila da Alegria foi designada uma área total de $853 \mathrm{~m}^{2}$. Atualmente encontra-se desocupada, está inserida entre duas edificações e um terreno ainda não ocupado. $\mathrm{O}$ estudo preliminar compreende moradias coletivas individuais para idosos com idade igual ou superior a 60 anos, com ou sem suporte familiar. São apresentadas duas opções de Plantas Baixas totalizando 32 leitos, projetados de forma a permitir a distribuição dos leitos em Alas Feminina e Masculina, conforme a demanda (Figura 05).

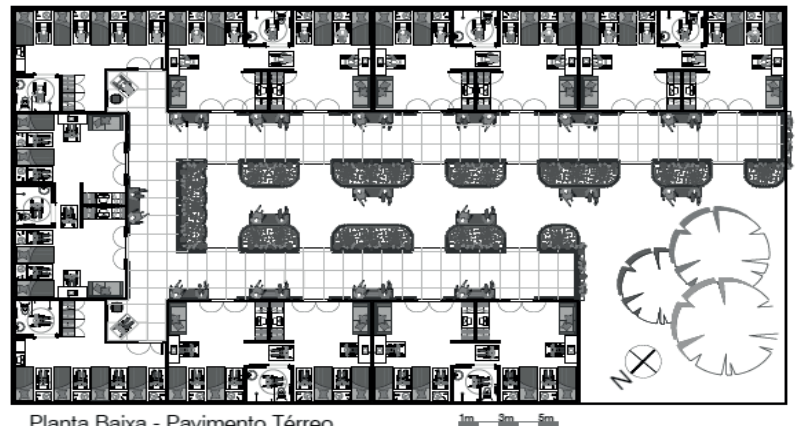

Planta Baixa - Pavimento Térreo $1 \mathrm{~m}-\mathrm{sm}^{\mathrm{m}}-\mathrm{sm}$

Figura 05 - Projeto Vila da Alegria - Planta Baixa. Fonte: acervo pessoal

\section{a. Dormitórios}

São apresentadas duas sugestões de plantas distribuídas de forma a ocupar 100\% do limite do terreno com aproveitamento dos muros laterais já edificados. No total são 8 quartos, sendo 6 (seis) quartos com planta Opção 1 e 2 (dois) quartos com Opção 2 (Figuras 06, 07 e 08).

A planta Opção 1 divide o aposento em dois quartos e permite que o idoso tenha mais privacidade. Também possibilita com que cada idoso possa ajudar a cuidar de outros 03 (três) idosos.

Para cada 4 (quatro) leitos há um banheiro adaptado ao portador de necessidades especiais. Nos banheiros, a ventilação acontece através de aberturas próximas ao teto e de forma cruzada. $\mathrm{O}$ revestimento das paredes e piso dos banheiros têm cores diferentes para demarcar visualmente o ambiente diferenciando o que é piso do que é parede.

Há local individual para cada idoso guardar objetos pessoais e uma pequena mesa onde o idoso pode exercer atividades tais como, tomar uma pequena refeição ou fazer alguma tarefa manual como pintura. Há também espaço reservado para uma estante para TV que na planta de Opção 1 fica em uma pequena sala de estar. 


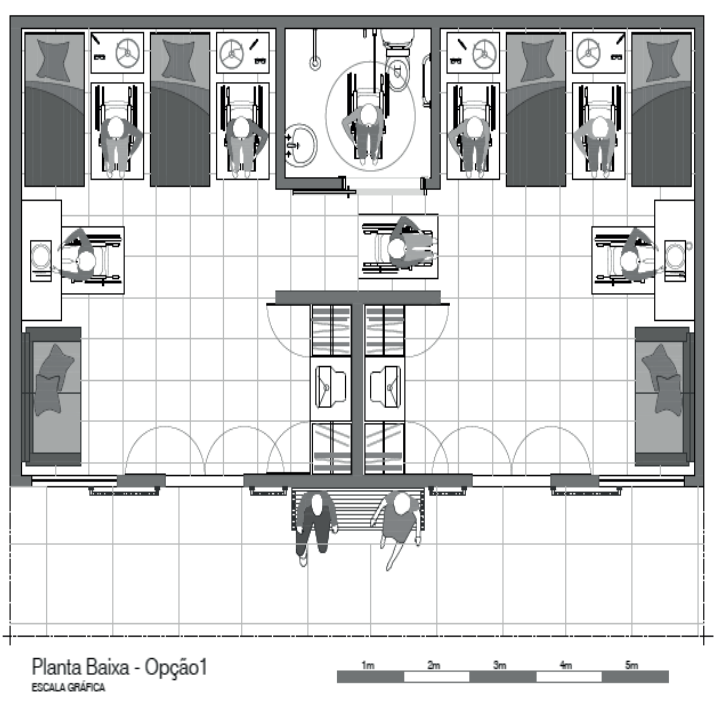

Figura 06 - Vila da Alegria - Planta Baixa Opção 1. Fonte: acervo pessoal

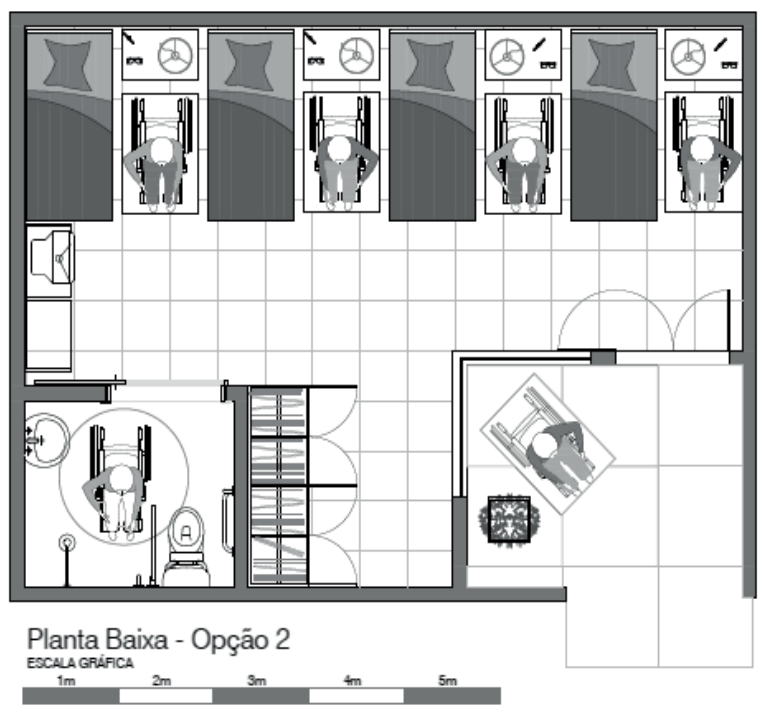

Figura 07 - Vila da Alegria - Planta Baixa Opção 2. Fonte: acervo pessoal

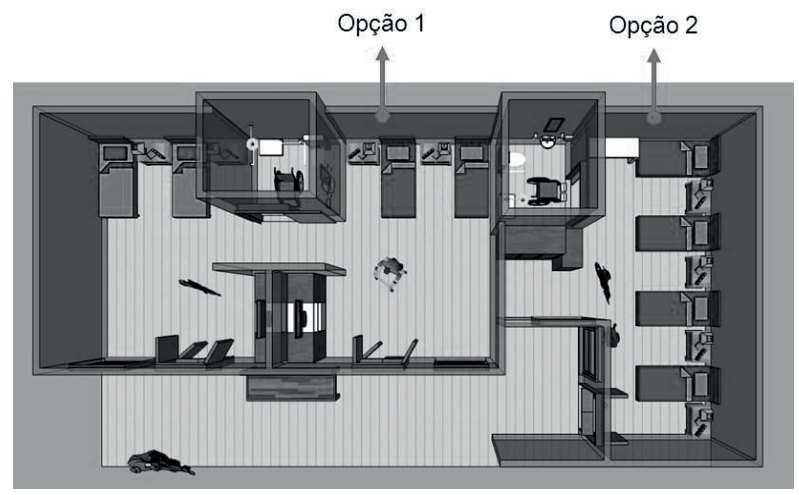

Figura 08 - Vila da Alegria - Perspectivas das plantas Opções 1 e 2. Fonte: acervo pessoal
O mobiliário é distribuído nas laterais dos quartos de forma a deixar a parte central do ambiente livre para a movimentação do idoso em cadeira de rodas, podendo se dirigir em qualquer direção (Figuras 09 e 10).

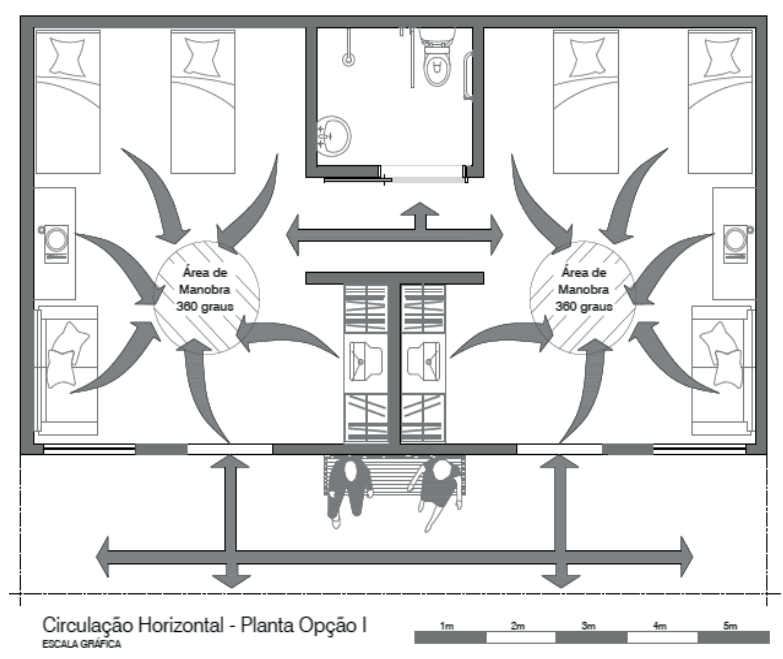

Figura 09 - Vila da Alegria - Circulação Horizontal. Fonte: acervo pessoal

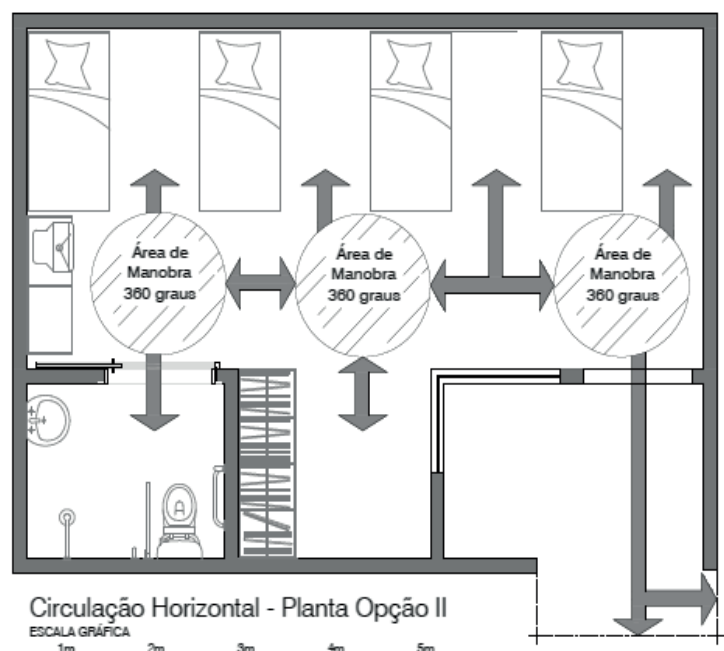
$\underset{1 \mathrm{~m}}{\text { ESCLASACA }}$ $3 m \quad 4 m \quad 5 m$

Figura 10 - Vila da Alegria - Circulação Horizontal. Fonte: acervo pessoal.

As camas ficam em posição frontal à porta de entrada do quarto e janelas, de forma que o idoso percorra a menor distância possível e também seja possível que ele, da cama, possa acompanhar as atividades que acontecem na varanda externa. As portas balcão têm a opção de deixar porta inteira ou meia porta aberta, o que pode significar um convite ao visitante entrar ou se comunicar com quem está dentro do quarto (Figuras 11 e 12). 


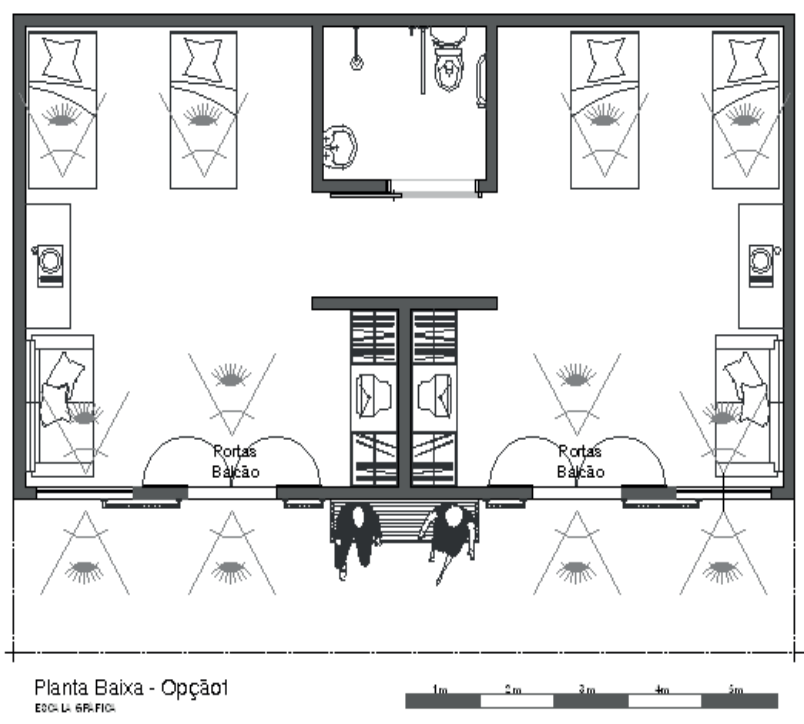

Figura 11 - Vila da Alegria - Posição das visuais. Fonte: acervo pessoal

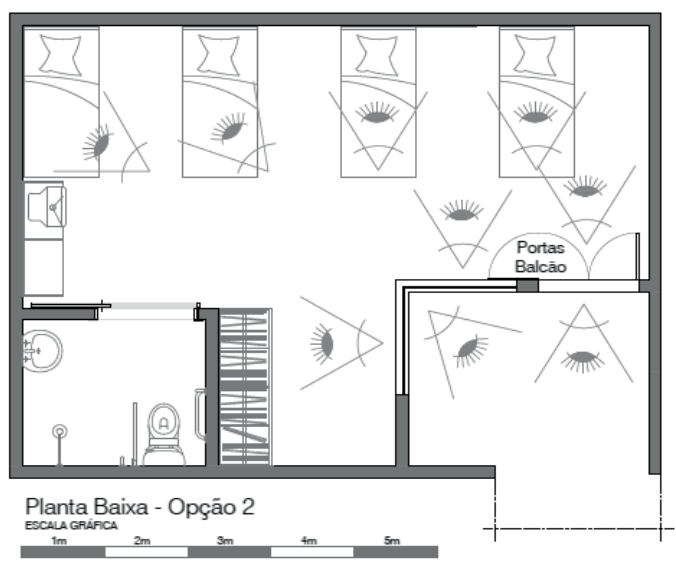

Figura 12 - Vila da Alegria - Posição das visuais. Fonte: acervo pessoal

\section{b. Varandas}

O corredor tem a função de uma "rua" de uma pequena cidade tradicional do interior, onde as pessoas usam para fazer uma caminhada ou mesmo ir visitar alguém que mora no quarto ao lado. As floreiras existentes ao longo da varanda estão estrategicamente localizadas próximas e em frente a cada unidade, o que faz com que cada idoso se torne responsável por cuidar e plantar cada uma delas. O idoso, ao optar por plantar flores ou frutas silvestres como morango, fará com que as cores e odores sejam alterados pelo caminho, à medida que ele percorre o trajeto. Esta atividade trará mais personalidade a cada fachada do quarto e ele poderá dizer com orgulho qual é a entrada para o seu quarto.

Os bancos, estrategicamente colocados pelo caminho, permitirão que o idoso pare para descansar um momento, ou mesmo, conversar com as pessoas que ali se encontram. O ir e vir de pessoas na "rua" deve atrair também a atenção dos idosos dentro do quarto. Ao longo da varanda são distribuídos corrimãos para que o idoso possa caminhar com independência e segurança (Figura 13).

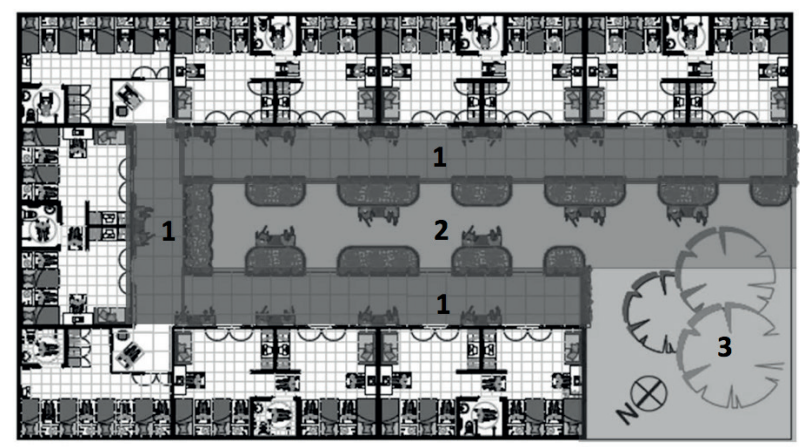

Figura 13 - Vila da Alegria - Atividades em varandas, pátio central e praça comunitária.

Fonte: acervo pessoal.

\begin{abstract}
Legenda
1 = Jardinagem por conta dos idosos.

2 = Jardinagem praticada por idosos e terceiros.

$3=$ Jardinagem praticada por idosos e terceiros
\end{abstract}

Da varanda o idoso tem a opção de caminhar até o pátio central onde também há floreiras que poderão ser utilizadas para plantar flores ou verduras e legumes, ou seja, uma horta, que também poderá ser cultivada pelos idosos com a ajuda de terceiros.

O Pátio Central será um espaço alternativo destinado a eventos musicais, apresentações de grupos teatrais, leitura de livros e poesias, colocação de telão para sessões de filmes cinematográficos e improvisação de um salão para baile entre os idosos. Por possuir uma localização estratégica entre as demais edificações, será um espaço a ser aproveitado por idosos de outras alas da instituição (Figura 02).

\section{c. Iluminação Natural}

Através da iluminação, o idoso, inconscientemente, se guiará em direção a uma menor ou maior intensidade de luz. A luz natural, em graus progressivos de intensidade, se fará presente na quantidade correta ao que o idoso necessita para desempenhar certas tarefas. No quarto, a pequena quantidade de luz natural que entra pela abertura zenital permite ao idoso perceber o início e final do dia, o que possibilitará ao relógio biológico do idoso despertar e/ou iniciar suas atividades diárias, bem 
como saber a hora de se preparar para dormir. Na varanda, poderá optar por estar em contato direto com a luz solar que filtra por aberturas zenitais e estar em locais de sombra. $\mathrm{Na}$ área central, fica um terceiro espaço totalmente descoberto (Figura 14).

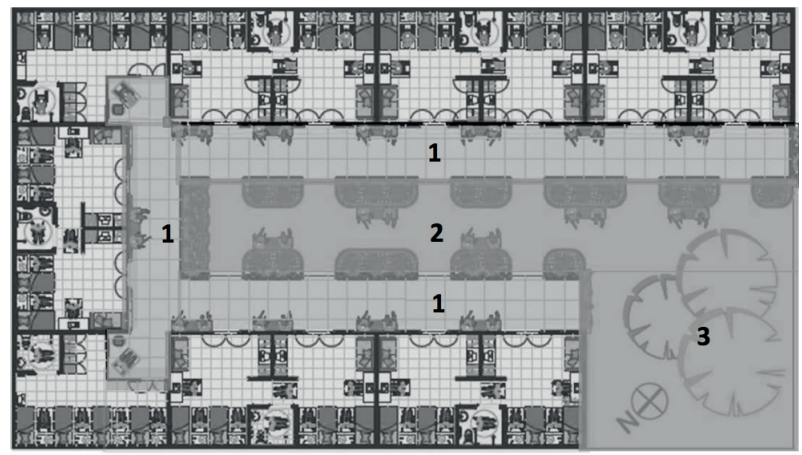

Figura 14 - Croqui esquemático - mostra a intensidade da luz natural nos ambientes.

Legenda

Fonte: acervo pessoal

1 = lluminação natural = 30\%

2 = lluminação natural $=80 \%$

$3=$ lluminação natural $=100 \%$

\section{d. Pisos}

Os pisos indicados para áreas internas e externas devem ser de superfície regular, firme, estável e antiderrapante e que não provoque trepidação em cadeira de rodas, de fácil manutenção, limpeza e conservação, uniformes, com ou sem juntas. A utilização de sinalização tátil de alerta, instalada em pontos estratégicos e a mudança de cor dos pisos, indica a mudança de ambiente e faz com que o idoso intuitivamente se localize no espaço (Figura 15).

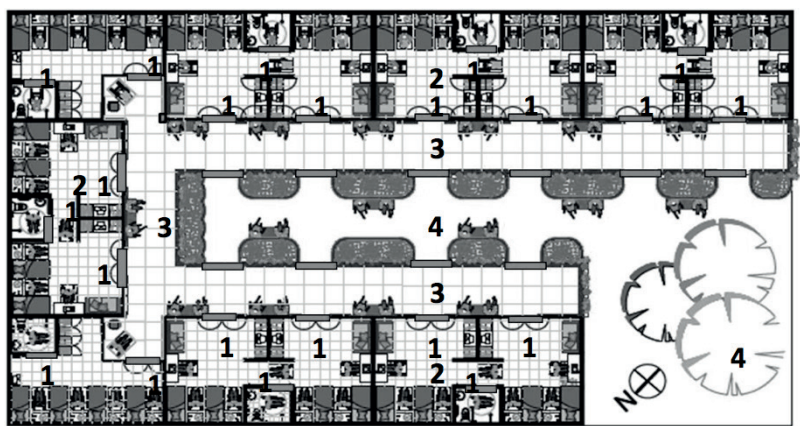

Figura 15 - Vila da Alegria - Planta paginação de piso. Fonte: acervo pessoal

Legenda

1 = Sinalização tátil de alerta de mudança de ambiente - alteração textura do piso.

2 = Piso área privativa - quartos e banheiros.

3 = Piso área comum - varanda.

4 = Piso pátio central e praça comunitária.

\section{e. Ventilação Natural}

Grandes são os benefícios que a ventilação natural traz aos ambientes ocupados pelo idoso, uma vez que ao permitir que a troca de ar aconteça dentro do ambiente, melhora as condições ambientes de odor e calor. No projeto ora apresentado, as janelas e portas são responsáveis pela renovação de ar, pois são as entradas do vento que passa pela varanda. Nos banheiros, a ventilação cruzada acontece na parte alta das paredes, permitindo, assim, a renovação de ar dentro dos banheiros, uma vez que a saída de ar quente e a entrada de ar frio acontecem pelas aberturas superiores (Figura 16).

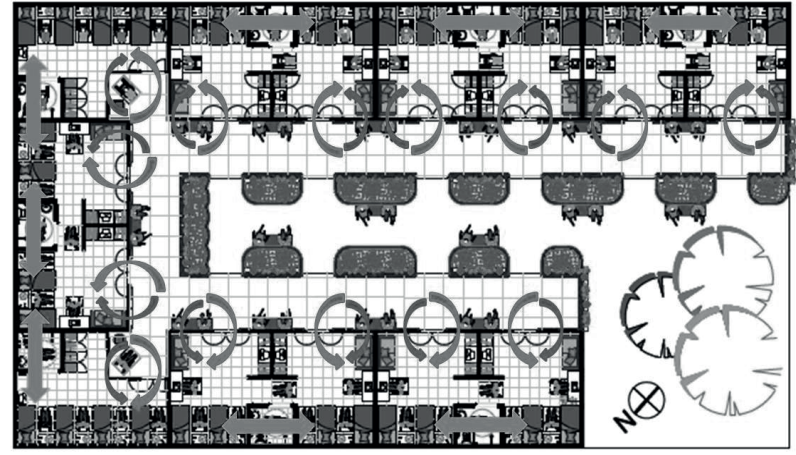

Figura 16 - Vila da Alegria - Ventilação Natural e cruzada Fonte: acervo pessoal.

Legenda

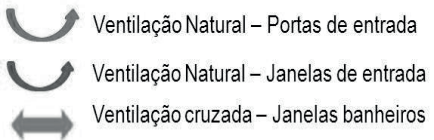

\subsection{Relação do idoso com o espaço ocupado}

Procurando fazer com que o idoso "habite" a Vila da Alegria, que foi especialmente preparada e pensada para ele, lança-se mão de elementos que tragam benefícios e atuem diretamente sobre o psiquismo humano. São elementos que trazem consigo a essência da noção de "casa", fazendo com que o idoso se identifique com o espaço, adote como sendo seu abrigo ao sentir segurança e aconchego.

A utilização de madeira como material utilizado nos corrimãos, apoio da cobertura, floreiras, portas e janelas, transmite sensação de proximidade, calor e conforto. A madeira traz a lembrança da infância, quando brincadeiras de crianças aconteciam nos quintais, onde balanços eram presos nos galhos das árvores e frutas eram colhidas diretamente nos pés das árvores frutíferas. O contato das mãos do idoso com o corrimão de madeira desperta sensações táteis diferentes das produzidas pelo corrimão de metal. 
Nos quartos, o espaço individual que o idoso tem para guardar objetivos pessoais possibilita a ele fazer o seu cantinho da memória, onde possa colocar fotos de familiares e pessoas queridas.

Cada idoso que se dedique a cuidar das floreiras e hortas terá a oportunidade de preparar a fachada do seu quarto, como se fosse a da sua casa.

Todo o espaço é preparado de forma que o idoso tenha independência para ir e vir com total liberdade. Os locais de convivência e reunião (salas de estar, varandas, pátio central e praça alternativa) são locais de encontro, levando o idoso à socialização e não ao isolamento.

O projeto de paisagismo contempla espaços para frutas comestíveis e flores para as floreiras que ficam na varanda, forrações, arbustos, palmeiras e grama para as floreiras localizadas no pátio central e árvores de médio e grande porte, forração, arbusto e grama nos canteiros da praça alternativa.

\section{Considerações finais}

Os resultados obtidos permitem concluir que há várias respostas aos questionamentos iniciais do que seja uma arquitetura humanizada voltada para o idoso e de como fazê-la. Os projetos destinados ao idoso são complexos e contemplar todas as etapas cujo planejamento inclui um local onde o idoso possa ter a sua privacidade e que seja seguro, tranquilo, que atenda às suas necessidades de locomoção, onde possa estar em contato com suas memórias e conviver com familiares sem ser dependentes destes; outro local onde possa ter uma vida social, que leve a prática de exercícios físicos e caminhadas, jogos com amigos, contato com a natureza e o saber do que acontece à sua volta ou com as outras pessoas. Tudo isto inserido de tal forma que permita ao idoso e à comunidade local condições de interagir entre si. Percebe-se aí a importância do arquiteto como pensador de todos estes mundos, que com a sua intuição, conhecimento e desejo, é capaz de fazê-los interagir entre si. Todo este pensamento constitui a humanização da arquitetura que, juntamente com legislação e normas técnicas, fecham o projeto.

Para que haja melhoria nos projetos para idosos, o Desenho Universal deve ser inserido em programas de formação de profissionais de arquitetura. As normas técnicas de uma arquitetura inclusiva devem integrar todos os projetos de arquitetura, possibilitando que toda habi- tação possa receber a visita de uma pessoa portadora de necessidades especiais ou mesmo ser adaptada para que o proprietário, deficiente ou não, possa utilizá-la por toda a vida.

A legislação de acessibilidade no Brasil refere-se à aplicação da NBR 9.050/2004, que não faz distinção entre jovens e idosos, tratando a todos como portadores de necessidades especiais. Mas, ao conhecer melhor o idoso aprende-se que suas necessidades são diferentes. Por exemplo, quando em cadeira de rodas, o idoso necessita de enfermeiro que o acompanhe e o espaço de manobra deve ter dimensão compatível prevento o giro da cadeira de rodas e a movimentação do enfermeiro.

Conclui-se também ter atendido a quesitos de servir como consulta teórica e prática para projetos de arquitetura; ter demonstrado como a qualidade de vida está ligada às questões de uma boa arquitetura; incentivar profissionais da área a mudar de comportamento e, por último, a conscientização da necessidade de se trabalhar uma legislação arquitetônica que inclua normas técnicas e comportamentais específicas para o idoso.

\section{Referências}

ASSOCIAÇÃO BRASILEIRA DE NORMAS TÉCNICAS. NBR 9.050/2004: acessibilidade a edificações, mobiliário, espaços e equipamentos urbanos. Rio de Janeiro, 2004.

ASSOCIAÇÃO BRASILEIRA DE NORMAS TÉCNICAS. NBR 9.077:2001: saídas de emergência em edifícios, Rio de Janeiro, 2001.

ATUALIDADES Imobiliárias. São Paulo, 2010. Disponível em <http://atualidadesimobiliarias.blogspot.com>. Acesso em: $01 \mathrm{dez} .2010$.

BACHELARD, Gaston. A poética do espaço. São Paulo: M. Fontes, 2000.

BRASIL. Decreto 5.296, de 02 de dezembro de 2004. Regulamenta a Lei 10.048 , de 08 de novembro de 2000 e a Lei 10.098, de 19 de dezembro de 2000. Disponível em $<$ http://www.planalto.gov.br $>$. Acesso em:

BRASIL. Lei 10.741 , de $1 .^{\circ}$ de outubro de 2003. Dispõe sobre o Estatuto de Idoso e dá outras providências. Disponível em $<$ http://www.planalto.gov.br $>$. Acesso em:

BRASIL. Lei 8.842, de 04 de janeiro de 1994. Dispõe sobre a política nacional do idoso, cria o Conselho Nacional do Idoso e dá outras providências. 
BRASIL. Resolução RDC n. ${ }^{\circ}$ 50, de 21 de fevereiro de 2002. Dispõe sobre o Regulamento Técnico para planejamento, programação, elaboração e avaliação de projetos físicos de estabelecimentos assistenciais de saúde. Disponível em <http://portal.anvisa.gov.br $>$. Acesso em:

BRASIL. Resolução RDC n. ${ }^{\circ} 283$, de 26 de setembro de 2005. Art. $1^{\circ}$ - Aprovar o Regulamento Técnico que define normas de funcionamento para as Instituições de Longa Permanência para Idosos - de caráter residencial - na forma do Anexo desta Resolução. Diário Oficial da União, Brasília, 2005.

DESIGUALDADE Social e Saúde entre idosos. Rio de Janeiro, 2003. Disponível em: <http://www.scielosp.org/ pdf/csp/v19n3/15878.pdf>. Acesso em: 26 abr. 2010.

HERTZBERGER, Herman. Lições de Arquitetura. São Paulo: M. Fontes, 1996.

INSTITUTO BRASILEIRO DE GEOGRAFIA E ESTATÍSTICA. [Séries estatísticas]. Disponível em: <http:// www.ibge.gov.br/series_estatísticas $>$. Acesso em: 29 ago. 2010 .
NÚCLEO DE PESQUISA E ESTUDOS HOSPITAL ARQUITETURA - NUPEHA. São Paulo, 2010. Disponível em: <http://www.hospitalararquitetura.com.br>. Acesso em: 03 maio 2010.

SÃO PAULO. Secretaria de Estado da Habitação. Desenho Universal Habitação de Interesse Social: cartilha diretrizes do desenho universal na habitação social de interesse social no estado de São Paulo: espaço para todos e por toda a vida. São Paulo: CDHU - Superintendência de Comunicação Social, 2010.

SÃO PAULO. Secretaria de Habitação. Programas habitacionais, 2009. Disponível em: <http://habitacao.sp.gov. $\mathrm{br} /$ programas-habitacionais/programas=-secretaria-dahabitacao/programa-viladignidade.asp $>$. Acesso em: 18 agosto 2010 .

ZEISEL, John. Low rise housing for older people: behavioral criteria for design. Michigan: University of Michigan Library, 1977. 